\title{
Reflections on osteopathic fascia treatment in the peripheral nervous system
}

This article was published in the following Dove Press journal:

Journal of Pain Research

30 October 2015

Number of times this article has been viewed

\author{
Bruno Bordoni ${ }^{1-3}$ \\ Giovanni Bordoni ${ }^{4}$ \\ 'Department of Cardiology, Santa \\ Maria Nascente Institute IRCCS - \\ Hospitalization and Care with \\ Scientific Address, Don Carlo \\ Gnocchi Foundation, ${ }^{2}$ School TCIO \\ Milano - Osteopathy Institute, \\ ${ }^{3}$ Edi-Ermes, Milan, ${ }^{4}$ CRESO School, \\ Osteopathic Centre for Research \\ and Studies, Falconara Marittima, \\ Ancona, Italy
}

\begin{abstract}
The peripheral nerve is composed of several layers of fascia tissue, which can become a source of pain if the way they slide is impeded. It is only recently that fascial osteopathy research has been aimed at understanding what happens to the fascia following treatment, and as a result of previous studies, we are able to highlight some of the benefits, including a reduction in local pain and inflammation. The osteopathic approach to the fascial system of the peripheral nerve does not have a grounding in scientific research, being based instead on the clinical experience of individual operators, despite peripheral nerve palpation being used as a method to evaluate and test its function. The authors wish to encourage the initiation of new research in the fields of academic and clinical osteopathy that is aimed at quantifying the possible benefits a patient may derive from osteopathic treatment of the peripheral nerve.
\end{abstract}

Keywords: pain, fascial treatment, nerve palpation

\section{Introduction}

The nerves and their structures change and are subject to the law of neuroplasticity: they adapt to reflect the stimulus which is present (mechanical, biochemical, electrical, or metabolic). ${ }^{1}$

The peripheral nervous system is subjected to a daily mechanical tensile load, as when a joint moves, undergoing compression and stretching. Compression happens when the surrounding tissues create a longitudinal force to a nerve, such as when the muscles are stretched, while stretching occurs when a force is parallel to the nerve, for example, when the elbow is flexed, the ulnar nerve is stretched. ${ }^{2}$ This mechanical stress can leave the physiological confines when there is direct trauma to the nerve or surrounding tissue. $^{2}$ The physiological tensile load allows the nerve to regenerate, through autocrine and paracrine substances, generated by the same nervous structure. When the nerve is subjected to stress in elongation, the Schwann cells can proliferate and synthesize many neurotrophic factors, which play roles in nerve repair and remodeling. ${ }^{3}$

The synthesized molecules are varied, with different functions depending on the site of production and the quantity and based on the combinations that occur; their direction and propulsion force also change. ${ }^{4,5}$ The synthesized molecules from nerve structure can travel along the nerve and stimulate the various receptors, activating or switching them off, so as to or not to interact with the molecule produced; the same molecules can behave in different modes based on the area where they were synthesized. ${ }^{4,5}$ In order for the nervous tissue to reshape correctly, it must have the ability to retain its elasticity. The correct sliding of the fascial structures that make up nerves and the sliding of nerves between the various tissues that cross and innervate it become
Correspondence: Bruno Bordoni Department of Cardiology, Santa Maria Nascente Institute IRCCS Hospitalization and Care with Scientific Address, Don Carlo Gnocchi Foundation, via Capecelatro 66, Milan 20142, Italy Tel +39023496300617

Email bordonibruno@hotmail.com 
fundamental, so that the mechanical stress can be communicated properly and has the ability to adapt and regenerate the nerves. ${ }^{6}$ An impediment to this slide will lead to dysfunction and pathology. ${ }^{7}$ The biochemical information carried by the nerve does not merely have the function of operating on the nervous system, but it is also able to assist trophism and tissue function that crosses the nerve and innervates it. Nerves can carry multipotent cells for repair and remodeling of tissues and organs, which are innervated by the same nerves. ${ }^{8}$

The fascial structure of a nerve is divided into three layers: the endoneurium, perineurium, and epineurium. All the layers are innervated and have a subtle but potentially important plexus of nociceptors. ${ }^{9}$

The epineurium is composed mainly of type I and III collagen, fibroblasts, mast cells, and fat cells. The interfascial epineurium is loosely attached to the perineurium, facilitating sliding of the various fascia. There is abundant epineurium in larger nerves, in order to disperse most of the compressive forces. The epineurium is attached to paraneural fascial components of the connective tissue that surrounds the nerve and is an extension of the dura mater. The vessels enter the epineurium in rolled-up form (to adapt better to the strain in elongation of the nerve) and periodically along its length, forming the vasa nervorum. Therefore, the epineurium supports the blood vessels while keeping the microvascularity of the nerve constant and also supports the nervi nervorum (sensory nerve fibers) of the nerve itself. It contributes to the tensile strength of the nerve and to the sliding, but it does not provide a barrier function. ${ }^{10,11}$

The perineurium surrounds the axon filaments with a dense connective tissue and the same perinerium is formed by up to 15 layers of flat perineural cells. We can encounter collagen type I and II, and other cells with different carriers modulating the tension recorded from the nerve, thereby regulating intraneural pressure. Perineural cells synthesize several substances and are in close contact with laminin and collagen type IV, further acting as a shock absorber. The perineurium is a much more elastic fabric than the epineurium. Another key task of the perineurium is to act as a blood barrier, ie, not allowing all the filtered substances to reach the endoneurium. Arterioles that reach and penetrate the perineurium form an oblique angle; these vessels have developed little smooth muscle and therefore do not possess a great intrinsic ability to regulate blood flow. Nevertheless, the perineurium performs important functions in the repair of nerve tissue by managing the traffic of molecules inside and out of the neural environment by active transcytotic transport. ${ }^{10,11}$ A study has shown the presence of many pinocytotic vesicles for this transcytosis, but more research is needed to draw conclusions. ${ }^{11}$ Molecules can also be transported via specific membrane receptors. ${ }^{11}$

The endoneurium contains individual axons wrapped several times by Schwann cells; this sheet is in turn wrapped by type IV collagen cells, fibronectin, laminin, and proteoglycans. Inserted between the various filaments, collagen type I and II with a longitudinal orientation, mast cells and macrophages, and endoneurial fluid (70\% water) can be found. The capillaries that penetrate the endoneurium increase in size, allowing the blood flow to head in different directions. The arterioles, however, are tightly wrapped by the endoneurium cells to create an additional barrier to the blood. It is most likely that the blood flow comes into contact with the endoneurium by diffusion. This ensures a constant pressure, with a slight positive pressure in this area. Venules carry the blood back to the venous system. The lymphatic system, however, is present only in the epineurium; there are no lymphatic drainage vessels into the nerves (Figure 1)..$^{10,11}$

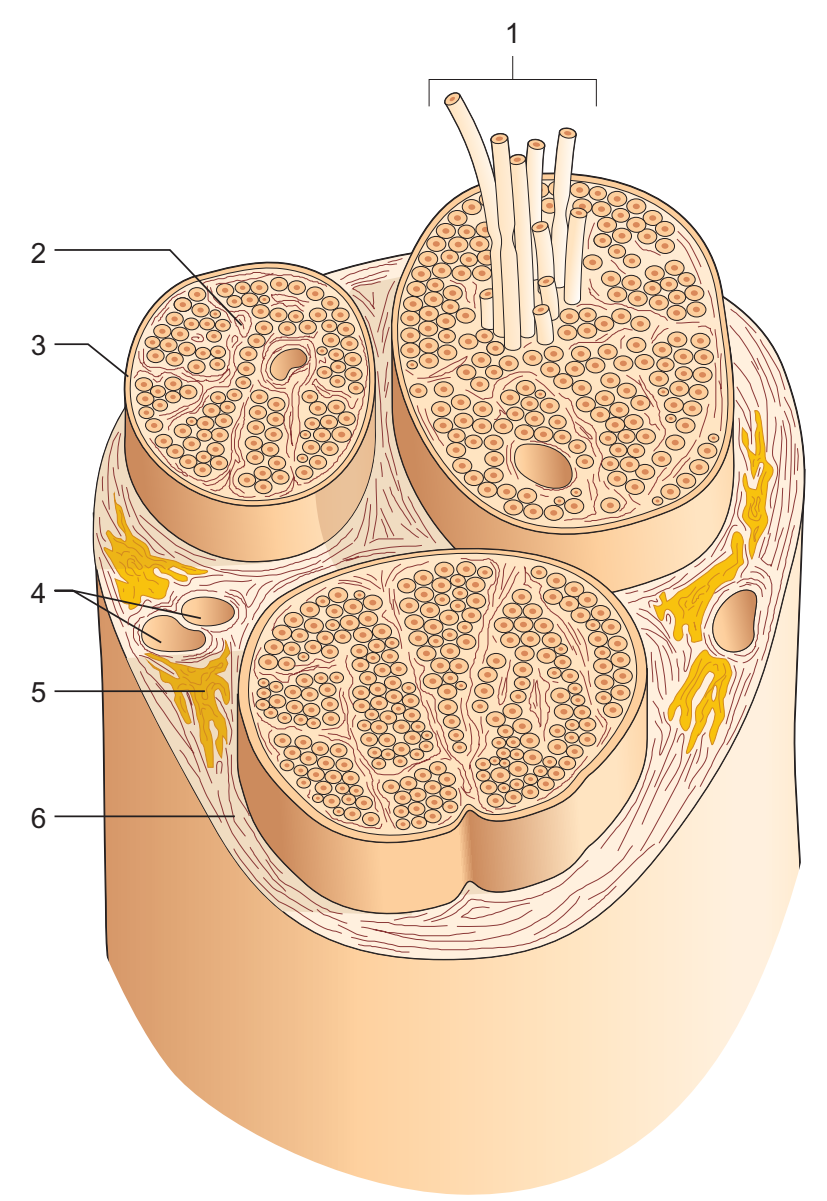

Figure I Constitution of a nerve in transverse section.

Notes: Pictured is the fasciculate architecture that is created following the organization operated by the connective tissue that forms the sheaths of the nerve and the individual bundles of fibers. I: Nerve bundles. 2: The endoneurium. 3: The perineurium. 4: Blood vessels. 5: Fat. 6: The epineurium. Reproduced with permission from Anastasi et al. AA VV, Anatomia dell'Uomo [Human Anatomy]. 4th ed. Milan: Edi.Ermes. Italian. ${ }^{30}$ Copyright 2010 Edi.Ermes, Milano. 


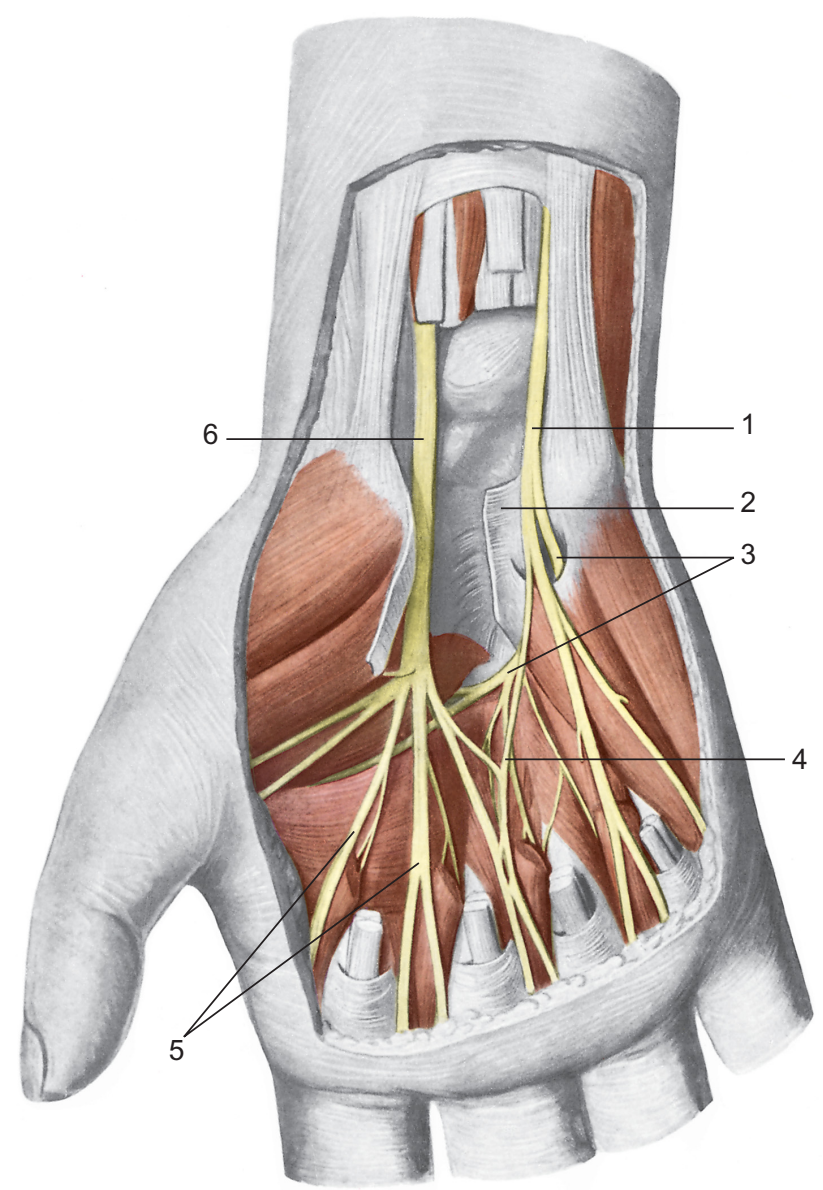

Figure $\mathbf{2}$ Location of the median and ulnar nerves in the region of the palm. Notes: I: The ulnar nerve; 2: the transverse carpal ligament; 3: deep palmar branch of the hand; 4: anastomosis between the median nerve and ulnar nerve; 5: digital nerves; 6: the median nerve. Reproduced with permission from Anastasi et al. AA VV, Anatomia dell'Uomo [Human Anatomy]. 4th ed. Milan: Edi.Ermes. Italian. ${ }^{30}$ Copyright 2010 Edi.Ermes, Milano.

The nervi nervorum, or a nerve's nerves, can evoke local neuroinflammation when there is nonphysiological damage or mechanical stress to the nerve tissue, to assist in its repair. ${ }^{9}$ The fascial nerve system innervated by the nervi nervorum may become a source of local pain. ${ }^{9}$ Another cause of pain by the fascial nerve system, connected to axonal and physiological dysfunctions and capable of generating dysesthetic or distant pain (for example, pain resulting from traction of the sciatic nerve, when the leg is stretched during tests), follows directly from the fascial structures of the axon. These fascial structures become more sensitive to mechanical stimulation and, after a few days of local inflammation, they are able to generate potential action similar to the mechanical stimulus that causes dysfunction. This mechanism is known as ectopic electrogenesis. ${ }^{9}$ Such nonphysiological situations may require from 1 week to 2 months to disappear and only involve the epineurium and perineurium. ${ }^{9}$ There is a strong hypothesis that impeded sliding of a nerve between its various layers and tissues that cross its fascial system will generate local and dysesthetic pain.
When there is an impediment to the sliding of a nerve, the rigidity of its fascial structures during joint movement is increased, and this is even more true when the joint is moved swiftly, which often occurs with everyday gestures. ${ }^{10}$ An elongated nerve causes a reduction in its diameter, defined as transverse contraction, with an increase in the pressure of the endoneurial compartment. ${ }^{10}$ Its return to size and length at rest happens due to the elasticity of the perineural tissue, while the endoneurial tissue has less elastic compliance. ${ }^{10}$ A decrease in the nerve's ability to stretch may damage the endoneurial integrity before a lesion to the epineurium is visible. ${ }^{10}$ Repetitive elongation of a nerve with reduced fascial elasticity properties brings about further inability of the nerve to slide, decreasing blood flow and likely leading to ischemic problems. ${ }^{10}$ For example, use of a computer mouse for prolonged periods leads to a reduction of the flow capacity of the median nerve at the level of the carpal tunnel, with possible pathological consequences of nerve compression, including the formation of edema, inflammation, and the production of adhesions, along with pain and reduced axonal flow (Figure 2).${ }^{10}$ Edema is found at the intraneural level and is a common response to trauma, compression, tension, or excessive vibration. A slight trauma may give rise to edema, more superficially, at the epineural level; this can be transformed into intraneural edema if compression continues, creating a mini-compartmental syndrome of the nerve, due also to the absence of lymphatic vessels in the endoneurium. All this will lead to fibrous adhesions, decreasing the sliding of the intrafascicular tissue. The fibrosis increases the compression both inside and outside the tissues with a thickening of the nerve. This is even more noticeable when the nerve passes through small areas. ${ }^{12}$ The situation described will still generate pain symptoms.

Many peripheral nerves can be palpated and directly moved, but at the same time, they are more susceptible to trauma than the central nervous system, which is protected by the cranium. ${ }^{9} 13$ Many peripheral nerves can be palpated and directly moved for anatomical reasons. ${ }^{9}$

\section{Fascial osteopathy}

There are very few texts in the scientific literature on manual treatment of the peripheral nervous system. Approaches using neurodynamics or neurodynamic mobilization techniques are more frequently observed. Such therapy is used by manual operators with the intent of allowing adequate sliding of the peripheral nerve and surrounding tissue, using two methods in particular: the sliding technique or a technique that alters the tension of the nerve path. ${ }^{13}$ Studies on the human model are scarce, and there are no precise data on the method of 
movement that should be performed on a patient's nerve path in order to optimize the results. Specific work protocols are lacking, and a positive clinic outcome is not always observed..$^{14-19}$

Within the field of osteopathy, there are no scientific articles that deal with palpation or manual techniques applied directly to the peripheral nerve, although there is a book that describes and shows how the osteopathic operator should palpate and treat emergencies superficial to the nerve path. ${ }^{20}$

The purpose of these therapies and treatments is to alter the mechanical properties of fascia, such as density, stiffness, and viscosity, so that the fascia can more readily adapt to physical stresses. In fact, some osteopathic physicians and manual therapists report local tissue release after the application of a slow manual force to tight fascial areas; these reports have been explained as a breaking of fascial cross-links, a transition from gel to sol state in the extracellular matrix, and other passive viscoelastic changes of fasciae. ${ }^{21}$ The fascial osteopathic technique is the application of a low-load, longduration stretch into the myofascial complex that is intended to restore the optimal length of this complex..$^{21}$ The operator places his or her hand on the fascial restriction identified previously by palpation, using different approaches, until the perceived resistance disappears or greatly decreases, inducing or stopping the preferential direction of the tissue..$^{21,22}$ The time required for the technique varies according to the response of the patient. ${ }^{22}$ There are reports in the literature that improvement in the sliding of the different fascia layers, via manual manipulation, may decrease pain symptoms and reduce inflammation at the local level..$^{21,23}$

Palpation of the peripheral nerves is feasible and is also used to evaluate nerve function, because these nerves are very often superficial..$^{24,25}$ Our clinical experience encourages us to support osteopathic fascial treatment of the peripheral nerve, providing a strong incentive to launch new research aimed at understanding what happens to the nerve using fascial osteopathic techniques, in addition to quantifying the benefit derived by the patient. It is important to remember that evidence-based medicine involves not only scientific research highlighted in an article, but also the patient's experience of treatment and the clinical experience of the operator. ${ }^{26}$

To provide some examples of treatment of peripheral nerve fascia, a finger or fingers are placed on the nerve emergence, either at the elbow on the cubital tunnel, where it passes the ulnar nerve (Figure 3), or in the middle third lateral of the humerus, where the radial nerve passes (Figure 4). ${ }^{24}$

Ulnar compression difficulties may be encountered at the cubital tunnel level, while the humeral area is subject to

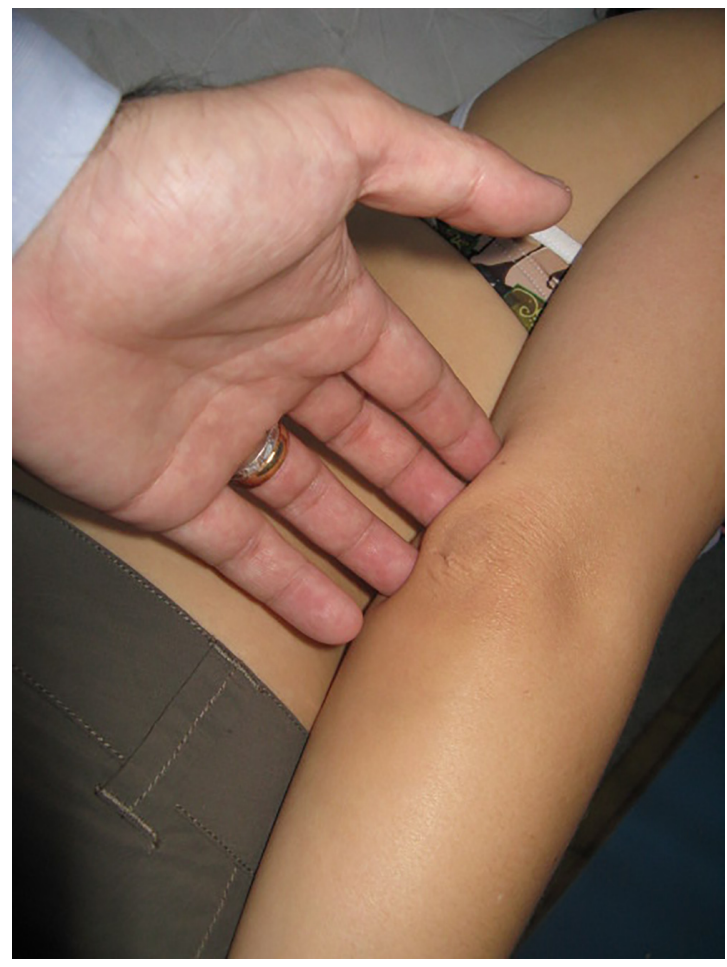

Figure 3 Fascial treatment of the ulnar nerve in the peripheral nervous system. Notes: A finger or fingers are placed on the nerve emergence at the elbow on the cubital tunnel, where it passes the ulnar nerve. The operator places his or her fingers on the fascial restriction identified previously by palpation, using different approaches, until the perceived resistance disappears or greatly decreases, inducing or stopping the preferential direction of the tissue.

direct trauma that might damage the radial nerve..$^{27-29}$ The method of treating any emergence of the peripheral nerve is relatively simple and noninvasive. Once the fingers are in contact with the emergence and the most superficial area of the nerve branches, a fascial osteopathic technique is used,

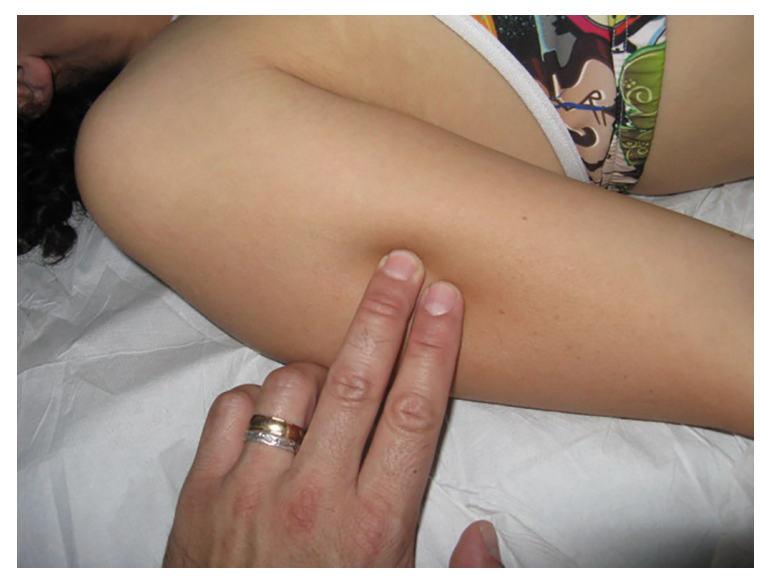

Figure 4 Fascial treatment of the radial nerve in the peripheral nervous system. Notes: A finger or fingers are placed on the nerve emergence in the middle third lateral of the humerus, where the radial nerve passes. The operator places his or her fingers on the fascial restriction identified previously by palpation, using different approaches, until the perceived resistance disappears or greatly decreases, inducing or stopping the preferential direction of the tissue. 
during which the operator waits for the tissues of the fabric to release under the fingers. ${ }^{21}$ It is common for the area being treated to be characterized by tissue hardness, with layers that slide with difficulty under the fingers: the technique ends when the tissue in the area has been restored, as close as possible, to a softer, more flexible tissue.

We do not know the exact scientific reasons for this fascial release, despite many studies showing that an osteopathic fascial treatment is useful in many clinical conditions. ${ }^{21}$ An in vitro study demonstrates how osteopathic techniques can influence the metabolic behavior of fibroblasts, such as proliferation and inflammatory response. ${ }^{21}$ Another possible explanation is that improved sliding of the various fascial layers would allow resetting of the afferents of the free nerve endings, resulting in a physiologic response of the efferents. ${ }^{21}$ Further studies are expected in order to facilitate choosing the best osteopathic approach to ensure the well-being of the patient.

\section{Conclusion}

The peripheral nerves are composed of several layers of fascial tissue, which can become a source of pain if they fail in their ability to slide. It is only recently that fascial osteopathy research has been aimed at understanding what happens to the fascia following treatment and, as a result of the first studies, it has been possible to highlight some of the benefits, including a reduction in local pain and inflammation. The osteopathic approach to the fascial system of the peripheral nerve does not have a grounding in scientific research, being based only on the clinical experience of individual operators, despite the use of peripheral nerve palpation as a method for the evaluation and testing of the nerve's function. The authors wish to encourage the initiation of new research in the fields of academic and clinical osteopathy that is aimed at quantifying the possible benefits a patient may derive from osteopathic treatment of the peripheral nerve.

\section{Acknowledgment}

The authors would like to thank their friend Fabiola Marelli, osteopath and director of the CRESCO School.

\section{Disclosure}

The authors report no conflicts of interest in this work.

\section{References}

1. Takeuchi N, Izumi S. Rehabilitation with poststroke motor recovery: a review with a focus on neural plasticity. Stroke Res Treat. 2013;2013: 128641.

2. Bueno FR, Shah SB. Implications of tensile loading for the tissue engineering of nerves. Tissue Eng Part B Rev. 2008;14(3):219-233.
3. Shao H, Shu H, Wang C, Yuan W, Li Y. Expression of nerve growth factor and its receptor in distracted tibial nerve after limb lengthening. Anat Rec (Hoboken). 2013;296(2):333-339.

4. Stoeckli E, Zou Y. How are neurons wired to form functional and plastic circuits? Meeting on Axon Guidance, Synaptogenesis and Neural Plasticity. EMBO Rep. 2009;10(4):326-330.

5. Dickson BJ, Cline H, Polleux F, Ghosh A. Making connections. Meeting: axon guidance and neural plasticity. EMBO Rep. 2001;2(3): 182-186.

6. Zhang L, Yang X, Yue Y, et al. Cyclic mechanical stress modulates neurotrophic and myelinating gene expression of Schwann cells. Cell Prolif. 2015;48(1):59-66.

7. Rickett T, Connell S, Bastijanic J, Hegde S, Shi R. Functional and mechanical evaluation of nerve stretch injury. J Med Syst. 2011;35(5): 787-793.

8. Ivashkin E, Voronezhskaya EE, Adameyko I. A paradigm shift in neurobiology: peripheral nerves deliver cellular material and control development. Zoology (Jena). 2014;117(5):293-294.

9. Bove GM. Epi-perineurial anatomy, innervation, and axonal nociceptive mechanisms. J Bodyw Mov Ther. 2008;12(3):185-190.

10. Topp KS, Boyd BS. Structure and biomechanics of peripheral nerves: nerve responses to physical stresses and implications for physical therapist practice. Phys Ther. 2006;86(1):92-109.

11. Peltonen S, Alanne M, Peltonen J. Barriers of the peripheral nerve. Tissue Barriers. 2013;1(3):e24956.

12. Brown CL, Gilbert KK, Brismee JM, Sizer PS, Roger James C, Smith MP. The effects of neurodynamic mobilization on fluid dispersion within the tibial nerve at the ankle: an unembalmed cadaveric study. J Man Manip Ther. 2011;19(1):26-34.

13. Wang Y, Ma M, Tang Q, Zhu L, Koleini M, Zou D. The effects of different tensile parameters for the neurodynamic mobilization technique on tricipital muscle wet weight and MuRf-1 expression in rabbits with sciatic nerve injury. J Neuroeng Rehabil. 2015;12:38.

14. Anandkumar S. The effect of sustained natural apophyseal glide (SNAG) combined with neurodynamics in the management of a patient with cervical radiculopathy: a case report. Physiother Theory Pract. 2015;31(2):140-145.

15. Villafañe JH, Pillastrini P, Borboni A. Manual therapy and neurodynamic mobilization in a patient with peroneal nerve paralysis: a case report J Chiropr Med. 2013;12(3):176-181.

16. De-la-Llave-Rincon AI, Ortega-Santiago R, Ambite-Quesada S, et al. Response of pain intensity to soft tissue mobilization and neurodynamic technique: a series of 18 patients with chronic carpal tunnel syndrome. J Manipulative Physiol Ther. 2012;35(6):420-427.

17. Oskay D, Meriç A, Kirdi N, Firat T, Ayhan C, Leblebicioğlu G. Neurodynamic mobilization in the conservative treatment of cubital tunnel syndrome: long-term follow-up of 7 cases. J Manipulative Physiol Ther. 2010;33(2):156-163.

18. Heebner ML, Roddey TS. The effects of neural mobilization in addition to standard care in persons with carpal tunnel syndrome from a community hospital. J Hand Ther. 2008;21(3):229-240.

19. Coppieters MW, Butler DS. Do 'sliders' slide and 'tensioners' tension? An analysis of neurodynamic techniques and considerations regarding their application. Man Ther. 2008;13(3):213-221.

20. Barral JP, Croibier A, Wetzler G. Manual Therapy for the Peripheral Nerves. Edinburgh: Churchill Livingstone; 2007.

21. Bordoni B, Zanier E. Understanding fibroblasts in order to comprehend the osteopathic treatment of the fascia. Evid Based Complement Alternat Med. 2015;2015:860934.

22. Chila AG, editor. Foundations of Osteopathic Medicine. Lippincott Williams \& Wilkins; 2010.

23. Bordoni B, Zanier E. Clinical and symptomatological reflections: the fascial system. J Multidiscip Healthc. 2014;7:401-411.

24. Schmid AB, Brunner F, Luomajoki H, et al. Reliability of clinical tests to evaluate nerve function and mechanosensitivity of the upper limb peripheral nervous system. BMC Musculoskelet Disord. 2009; 10:11. 
25. Khambati FA, Shetty VP, Ghate SD, Capadia GD. Sensitivity and specificity of nerve palpation, monofilament testing and voluntary muscle testing in detecting peripheral nerve abnormality, using nerve conduction studies as gold standard; a study in 357 patients. Lepr Rev. 2009;80(1):34-50.

26. Masic I, Miokovic M, Muhamedagic B. Evidence based medicine-new approaches and challenges. Acta Inform Med. 2008;16(4):219-225.

27. Polatsch DB, Melone CP Jr, Beldner S, Incorvaia A. Ulnar nerve anatomy. Hand Clin. 2007;23(3):283-289.
28. Łasecki M, Olchowy C, Pawluś A, Zaleska-Dorobisz U. The snapping elbow syndrome as a reason for chronic elbow neuralgia in a tennis player - MR, US and sonoelastography evaluation. Pol J Radiol. 2014;79: 467-471.

29. Ljungquist KL, Martineau P, Allan C. Radial nerve injuries. J Hand Surg Am. 2015;40(1):166-172.

30. Anastasi et al. AA VV, Anatomia dell'Uomo [Human Anatomy]. 4th ed. 2010, Milan: Edi.Ermes. Italian.

\section{Publish your work in this journal}

The Journal of Pain Research is an international, peer-reviewed, open access, online journal that welcomes laboratory and clinical findings in the fields of pain research and the prevention and management of pain. Original research, reviews, symposium reports, hypothesis formation and commentaries are all considered for publication.

\section{Dovepress}

The manuscript management system is completely online and includes a very quick and fair peer-review system, which is all easy to use. Visit http://www.dovepress.com/testimonials.php to read real quotes from published authors. 